Research Article

\title{
Investigation on Surrounding Rock Stability Control Technology of High Stress Roadway in Steeply Dipping Coal Seam
}

\author{
Honglin Liu $\mathbb{D}^{1,2}$ Chen $\mathrm{Xu}^{3}{ }^{3}$ Hongzhi Wang, ${ }^{1,2}$ Guodong Li, ${ }^{1,2}$ and Sanyang Fan ${ }^{3}$ \\ ${ }^{1}$ College of Geology and Mines Engineering, Xinjiang University, Urumqi 830046, China \\ ${ }^{2}$ Key Laboratory of Environmental Protection Mining for Minerals Resourses at Universities of \\ Education Department of Xinjiang Uygur Autonomous Region, Xinjiang University, Urumqi 830047, China \\ ${ }^{3}$ Xinjiang Hongxin Coal Industry Co., Ltd, China National Coal Group Corporation, Changji 831200, China \\ Correspondence should be addressed to Honglin Liu; liuhonglin@xju.edu.cn
}

Received 8 April 2021; Revised 4 June 2021; Accepted 29 June 2021; Published 18 August 2021

Academic Editor: Zizheng Zhang

Copyright (c) 2021 Honglin Liu et al. This is an open access article distributed under the Creative Commons Attribution License, which permits unrestricted use, distribution, and reproduction in any medium, provided the original work is properly cited.

\begin{abstract}
There are a large amount of steeply dipping coal seams deposited in China, the safe and effective extraction of which are the challenge for coal operators due to the complicated geological characteristics, in particular, when the underground roadway is excavated in the steeply dipping coal seams with limited seam distance. The Universal Distinct Element Code (UDEC) was adopted in the present research to explore the stress distribution of surrounding rock of the roadway. Based on the numerical simulation, the damage coefficient was proposed and then used to classify the roof conditions into four groups. After that, the asymmetric support technique was proposed and put into practical applications. It is indicated that the stress concentration on the floor is the main feature of the extraction of steeply dipping coal seams. Moreover, the distributions of the maximum vertical stress and horizontal stress which are much different from each other mainly attributed to the effect of the large dip angle. This research also verified the feasibility of using the asymmetric and partition support technique to maintain the integrity of the surrounding rock, as from the case study conducted at the 12032 longwall coal face of Zhongwei coal mine.
\end{abstract}

\section{Introduction}

The development of the mining industry in Xinjiang, one of the largest coal fields in China, is currently in the rapid and sustainable progress. The large thickness and shallow depth are the two attractive features of the coal seams in Xinjiang, which make it the ideal mining field to build the huge coal mines. Different from its counterparts exposited in other coal fields, however, the steeply dipping coal seam accounts for over 25\%; the proven reserves in China attributed to the unique diagenetic environment $[1,2]$. It has been well noted that the extraction of steeply dipping coal seams is difficult due to its unique geo-mechanical condition. The movement of the overlying strata upon the steeply dipping coal seam is much different with the increase of the dip angle. In particular, the large abutment pressure applied on the surrounding rock will significantly affect the stability of the roadway. This situation will be more serious when the adjacent coal seams with close distance are extracted $[3,4]$. How to effectively control the unexpected deformation of surrounding rock and maintain the integrity of the roadway is now the hot research topic to be considered either from the insight of the underground coal operators or the scientific scholars.

Various studies have been conducted to obtain an indepth understanding of the underground pressure distribution characteristics during the excavation of steeply dipping coal seam. As reported by $\mathrm{Wu}$ et al. [5-7], the excavation of upper coal seam will significantly affect the stability of the "R-S-F" system of the lower coal seam. Their research also indicated that both the underground pressure and the migration law of the steeply dipping coal seam is much different from other coal seams with small dip angle. The development and establishment of the asymmetrical structure is closely related to the stability of the longwall, which agrees well with the research carried out by Tu et al. 
$[8,9]$. Based on the geological and mining condition of Huainan mining zone, Yang and Kong studied the mutual superposition and evolution mechanism of underground pressure during the excavation of the steeply dipping coal seams as well [10-12]. It can be found from their research that the failure mechanism and stress distribution of the mining floor will be affected with the increase of the dip angles. In general, most studies did pay attention to the stress distribution and deformation failure of the surrounding rock with the excavation of two-layer coal seams.

Against this background, this paper presents a comprehensive research to obtain a better understanding on the mechanical mechanism and deformation characteristics of the surrounding rock for the roadway located in the steeply dipping coal seam. It starts with a concise introduction about the research area, followed by the detailed numerical modelling of the excavation procedure of the roadway in the steeply dipping coal seams. This paper ends up with the filed investigation to verify the proposed controlling technique. The meaningful research outcomes can be used as the guideline for other underground coal mines in Xinjiang coal fields where there are similar geological and mining conditions.

\section{Geological and Mining Conditions of the Research Area}

Zhongwei Coal Mine, which is operated by Henan Energy and Chemical Industry Group Co., Ltd., is located in Baicheng, Xinjiang. The single-entry longwall operation is adopted to excavate the IV13 coal seam. The coal seam featured with its large dips ranging from $25^{\circ}$ to $50^{\circ}$, with the average value of $35^{\circ}$. Except for the large dip angle, the variable thickness of the IV13 coal seam is the other concern to be accounted for. As depicted in Figure 1, the normal thickness of the IV13 coal seam is within 0.87 to $10.92 \mathrm{~m}$, with the average thickness of $3.67 \mathrm{~m}$. Note that the IV13 coal seam has to be mined separately (see Figure 1(a)). For ease of reference, these spilt coal seams are termed as $I V 13^{\mathrm{a}}$ and IV13 ${ }^{\mathrm{b}}$, respectively. Currently, the upper subsection termed IV $13^{\mathrm{a}}$ has been totally extracted and the preparation of 12032 longwall is still in progress.

As the first longwall located in the lower subsection (i.e., IV $13^{\mathrm{b}}$ ), the strike length and the trend length of the 12032 longwall are $691 \mathrm{~m}$ and $161.7 \mathrm{~m}$, respectively. The ground elevation is $+2730 \sim+2900 \mathrm{~m}$ and the elevation of 12032 longwall is $+2315 \pm 2400 \mathrm{~m}$. As depicted in Figure 1(b), the coal resource around the 12032 longwall has been completely extracted. The $2.07 \mathrm{~m}$ thickness $\mathrm{IV} 13^{\mathrm{b}}$ coal seam is fully excavated. More detailed information about surrounding rock is shown in Table 1 .

\section{Numerical Modelling of the Excavation of Steeply Dipping Coal Seams}

3.1. Setup of the Numerical Model. The redistribution of the underground pressure will result in the development of fissures of surrounding rock, generally associated with the large deformation of the excavated zone $[13,14]$.
Considering that the distribution and transmission law of surrounding rock is the foundation to further investigate the damage process of the surrounding rock, the two-dimensional numerical program, Universal Distinct Element Code (UDEC), was applied to simulate the extraction progress of coal resource in the 12032 longwall.

As shown in Figure 2, the length and height of the UDEC Trigon model are $250 \mathrm{~m}$ and $150 \mathrm{~m}$, respectively. Herein, both the coal seam and surrounding rocks are all simply defined with the dip angle of $35^{\circ}$, equivalent to the average dip angle of the coal seam. The boundaries of the numerical model were fixed according to the practical conditions. Note that the vertical stress applied on the upper boundary is 7.2 MPa based on the average mining depth of $300 \mathrm{~m}$. The Mohr-Coulomb yield criterion was given to the interface, while the elastic model was applied for block element $[15,16]$. Four monitoring lines were distributed along the floor of IV $13^{\mathrm{a}}$ coal seam to record the value of stress. The uniform space between each monitoring line is $1 \mathrm{~m}$.

Different from the conventional finite element modelling method (FEM), the critical parameters for the UDEC Trigon model cannot be directly obtained from the calibration of experimental tests. Thus, the micromechanical parameters of layered polygonal block and contact interface were obtained from existing open literature [17-21]. The values of these critical input parameters including the internal friction angle $(\phi)$, the cohesive force $(C)$, and the tensile strength $(T)$ of the contact surface are summarized in Table 1. In addition, the micromechanical parameters of polygonal block are also shown in Table 1.

3.2. Stress Distribution of Floor. In accordance with the practical mining process, the upper coal seam (i.e., IV13 ${ }^{\mathrm{a}}$ ) was firstly excavated with a $15 \mathrm{~m}$-width coal pillar left. Figure 3 presents the stress Mises distribution around the gob and the floor of the coal pillar. Herein, the stresses including the vertical stress, horizontal stress, and shear stress were plotted in Figure 4, the values of which were obtained from the embedded monitoring lines mentioned earlier.

As can be seen from Figures 3 and 4, there is an obvious stress concentration under the coal pillar after the excavation of the IV $13^{\mathrm{a}}$ coal seam, whereas, the monitored stresses around the gob floor exhibit somewhat reduction. For ease of reference, the ratio between the monitored stress and the in situ stress is defined as stress concentration factor (SCF). Note that the initial horizontal stress and vertical stress are 10.8 $\mathrm{MPa}$ and 9.0 $\mathrm{MPa}$, respectively. The maximum vertical stress was obtained from the center line of the coal pillar (larger buried depth side) with the value of $25.2 \mathrm{MPa}$ $(\mathrm{SCF}=2.8)$. It can also be found that the peak value of the horizontal stress is $22.7 \mathrm{MPa}(\mathrm{SCF}=2.1$ ), which is obtained from the upper side of the center line. If the vertical distance between the floor and the coal pillar is within $4.0 \mathrm{~m}$, both the vertical stress and the horizontal stress concentration coefficients will experience the gradually increase with the enlargement of the vertical distance.

With the increased horizontal distance apart from the center line in the coal pillar, both the vertical stress and the 


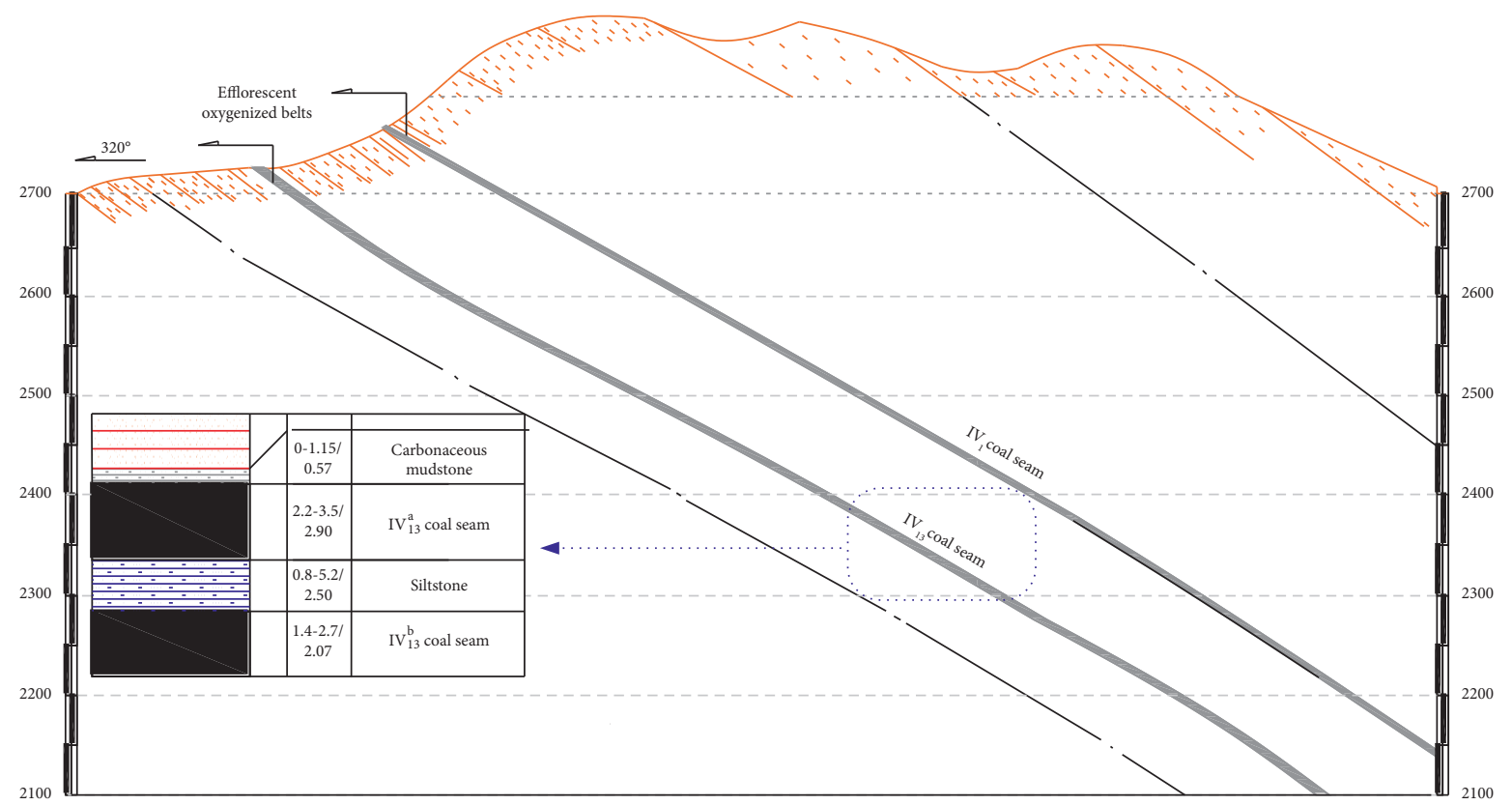

(a)
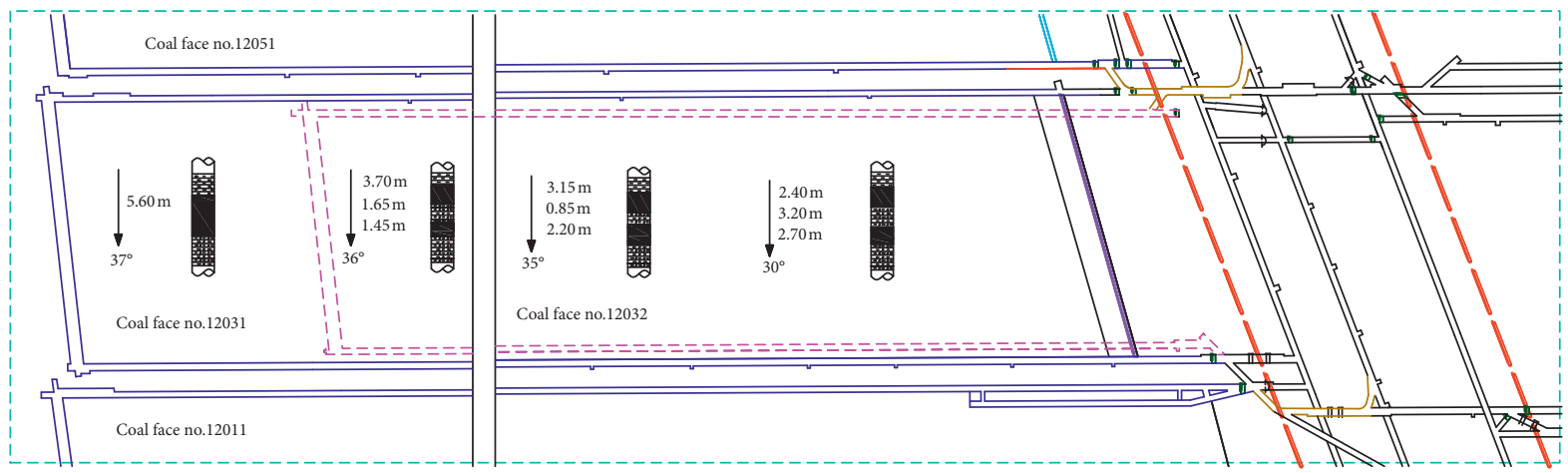

(b)

FIGURE 1: Geological survey of research object: (a) geological section of coal seam no. IV13 and (b) roadway layout of 12032 coal face.

TABLE 1: Micromechanical parameters of each layered rock of the model.

\begin{tabular}{|c|c|c|c|c|c|c|c|}
\hline \multirow[b]{2}{*}{ Lithology } & \multicolumn{3}{|c|}{ Block parameters } & \multicolumn{4}{|c|}{ Contact surface parameters } \\
\hline & $\begin{array}{c}\text { Density } \\
\left(\mathrm{kg} \cdot \mathrm{m}^{-3}\right)\end{array}$ & $\begin{array}{c}\text { Elastic modulus } \\
(\mathrm{GPa})\end{array}$ & $\begin{array}{l}\text { Bulk modulus } \\
\quad(\mathrm{GPa})\end{array}$ & $\begin{array}{c}\text { Shear modulus } \\
(\mathrm{GPa})\end{array}$ & $\begin{array}{c}\text { Friction } \\
\text { angle }\left(\left(^{\circ}\right)\right.\end{array}$ & $\begin{array}{c}\text { Cohesion } \\
(\mathrm{MPa})\end{array}$ & $\begin{array}{c}\text { Tensile strength } \\
(\mathrm{MPa})\end{array}$ \\
\hline $\begin{array}{l}\text { Carbonaceous } \\
\text { mudstone }\end{array}$ & 2500 & 5.30 & 24.40 & 9.70 & 18 & 1.5 & 0.5 \\
\hline Coal seam & 1300 & 2.60 & 11.50 & 4.60 & 14 & 0.8 & 0.32 \\
\hline Mudstone & 2500 & 3.80 & 24.40 & 9.70 & 18 & 1.3 & 0.4 \\
\hline Sandstone & 2500 & 10.04 & 28.70 & 9.50 & 21 & 0 & 0 \\
\hline
\end{tabular}

horizontal stress experience the obvious decline, which are approximately in accordance, with a normal distribution, with each other. However, the attenuation speed for vertical stress and horizontal stress is much different. In detail, the attenuation trend of the vertical stress nearby the upper side of the central line is more obvious compared to its counterpart. Differently, the attenuation of the horizontal stress nearby the upper side of the central line seems to be significant.
It is interesting that the peak shear stresses recorded from each side are much different from each other. The peak shear stress upon the center line with the smaller mining depth is generally larger than that obtained from the other side. In particular, the value of SCF will also experience the reduction with the increase of the depth, when the distance between the floor and the coal pillar is within $4 \mathrm{~m}$.

Based on the above discussions, it can be summarized that there exists the stress concentration on the floor of the 


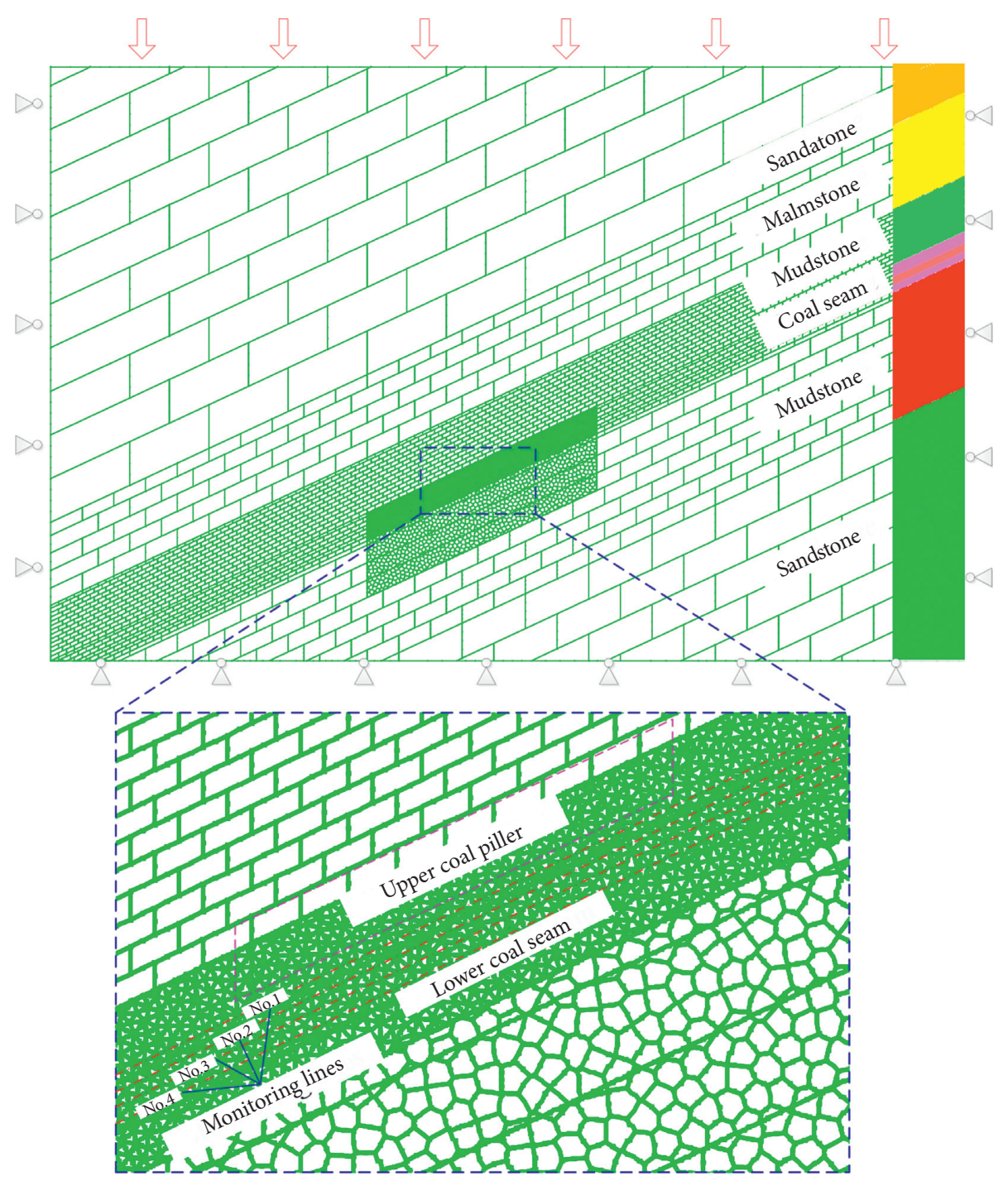

Figure 2: Numerical calculation model.

residual coal pillar. The maximum vertical stress is generally below the centerline of the coal pillar, while the maximum horizontal stress is above the centerline of the coal pillar. In general, the peak shear stress above the centerline of the coal pillar is generally larger than that obtained from the other side.

\section{Damage Regulation of the Floor}

4.1. Definition of the Damage Coefficient. A large number of laboratory tests have revealed that the microstructure will affect the mechanical properties of intact rock and coal mass [22-24]. Although the coal/rock mass are heterogeneity in natural from the microscopic insight, it can still be evaluated and presented by the Weibull statistical distribution. Herein, the damage coefficient is defined with the following considerations: (1) it should sufficiently reflect the characteristics of rock mass damage and (2) it is feasible to obtain the value by the actual measurement technique.

In this research, the damage coefficient was adopted in the respect of the numerical simulation. That is, the ratio between the contact length (e.g., shear or stretch) of the failed block and the total length of all blocks is used to evaluate the development density and penetration of fractures in coal/rock masses.

4.2. Damage Characteristics of the Floor. Figure 5 presents the damage characteristics of floor rock after the excavation of the upper IV $13^{\mathrm{a}}$ coal seam, in which the types of the failure are marked in different colors. It is apparent that the floor rock is featured with the shear failure. Moreover, many shear cracks and tensile cracks were observed from the affected zone within $6 \mathrm{~m}$ apart from the central line of the coal pillar. With the increase of the distance, apart from the coal pillar, the number of cracks nearby the edge of coal pillar exhibit a significantly decrease. In addition, the floor is generally dominated by the tension cracks. The tensile cracks are widely distributed around the edge of the coal pillar within the $20 \mathrm{~m}$ zone. Both the number of cracks and the crack penetration experience the reduction when the distance apart from the center line is over $20 \mathrm{~m}$. 


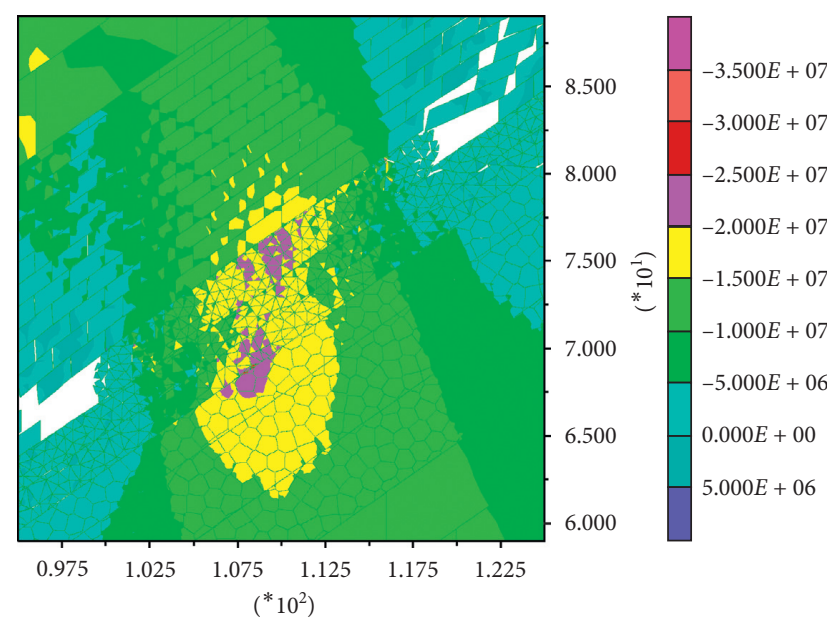

(a)

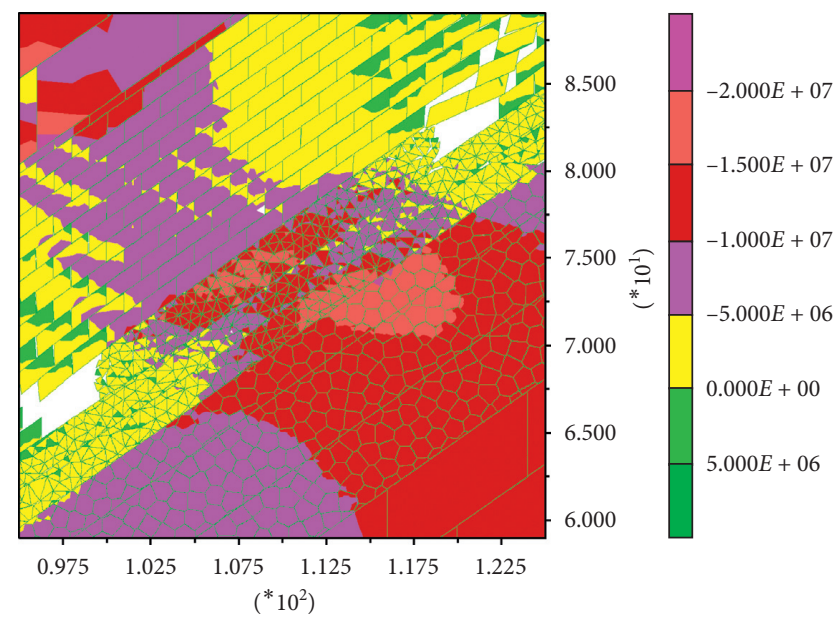

(b)

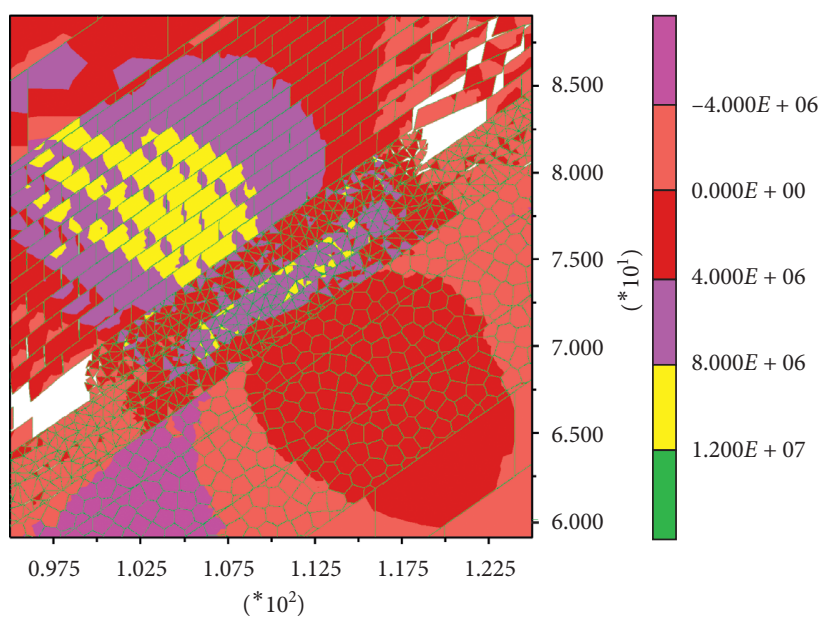

(c)

FIGURE 3: Stress distribution characteristics in the floor of goaf and coal pillar: (a) vertical stress, (b) horizontal stress, and (c) shear stress.

With the consideration of the rock damage at different locations (e.g., coal pillar, floor, and lower coal seam), the additional monitoring line was arranged along the perpendicular side to the surrounding rock. The distribution of the damage coefficient can be found from Figure 6, in which the values of the damage coefficient were theoretically calculated according to its definition. It can be seen from Figure 6 that the damage coefficient of the floor under the coal pillar ranges from $12 \%$ to $50 \%$. In addition, the damage coefficient of the surrounding rock above the center line is generally larger than its counterpart. Because the compressive strength of coal seam is much smaller than that of surrounding rock, the damage of the lower coal seam seems to be serious than that of the floor, which is about 19 64\%, as shown in Figure 6.

\section{Classification of the Roof Conditions Based on the Damage Coefficient}

The predicted distances between the IV $13^{\mathrm{a}}$ and IV $13^{\mathrm{b}}$ coal seams in the 12302 longwall are listed in Tables 2 and 3, the values of which are obtained from the actual exposure of the strata as well as the exploration data. Compared with the predicted values (e.g., $0.85-3.90 \mathrm{~m}$ ), the damaged depth of surrounding rock (e.g., $1.50-3.50 \mathrm{~m}$ ) are generally larger, indicating that most surrounding rocks are damaged due to the mining activities. Thus, the roof of the roadway can be correspondingly classified into four groups, as listed in Table 4.

Type I (broken and loose roof): the coal pillar is failed with the shear slip at its bottom edge, mainly attributed to the combined effects of the abutment pressure and the front strata pressure. The roof will be completely crushed if the distance between two coal seams is within $1.5 \mathrm{~m}$. The main feature of this type roof is its loose structural after the drilling of the roadway in the lower coal seam.

Type II (crack-extended roof): under the combined influence of front strata pressure and the abutment pressure, there will be lots of cracks and fissures. However, the integrity of the roof can be sustained when the distance between the coal seams ranges from $1.5 \mathrm{~m}$ to $2.5 \mathrm{~m}$. 

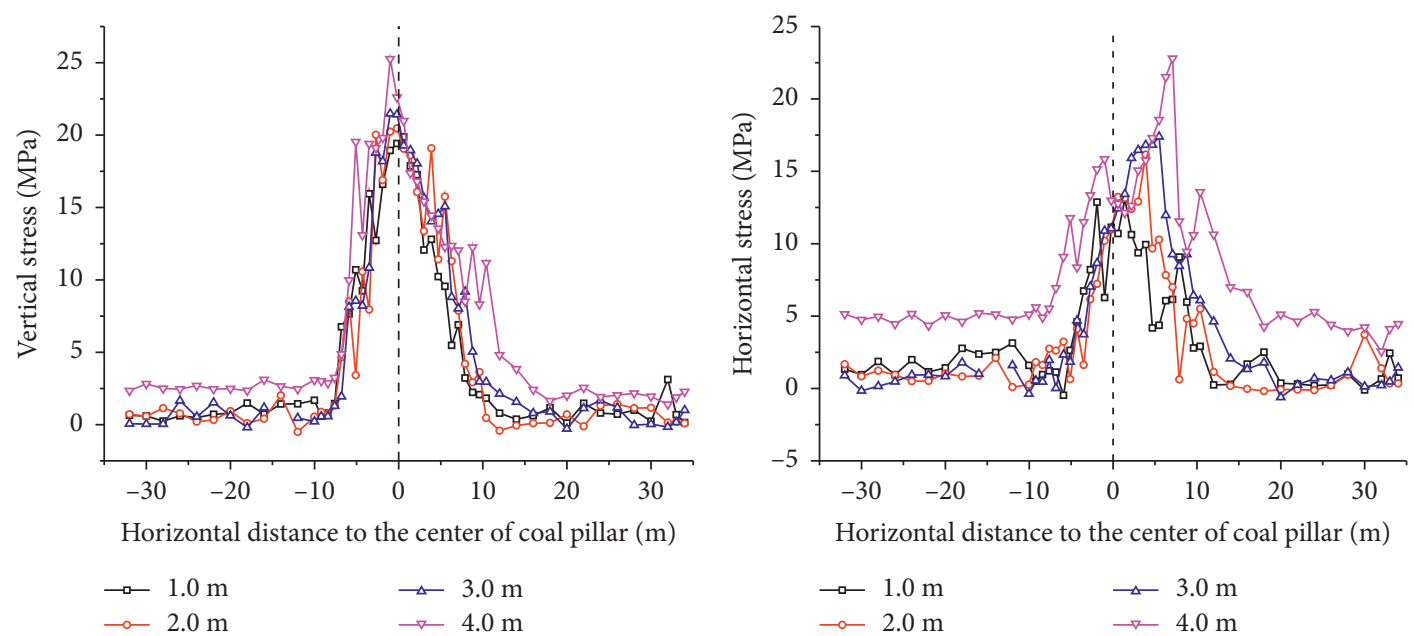

(a)

(b)

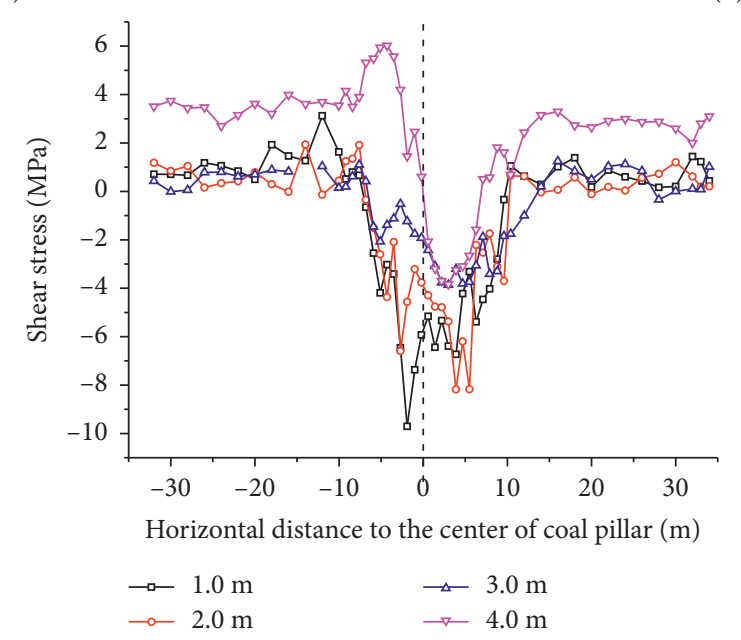

(c)

FIGURE 4: Stress distribution in different depths of floor: (a) vertical stress distribution of floor and (b) horizontal stress distribution of floor.

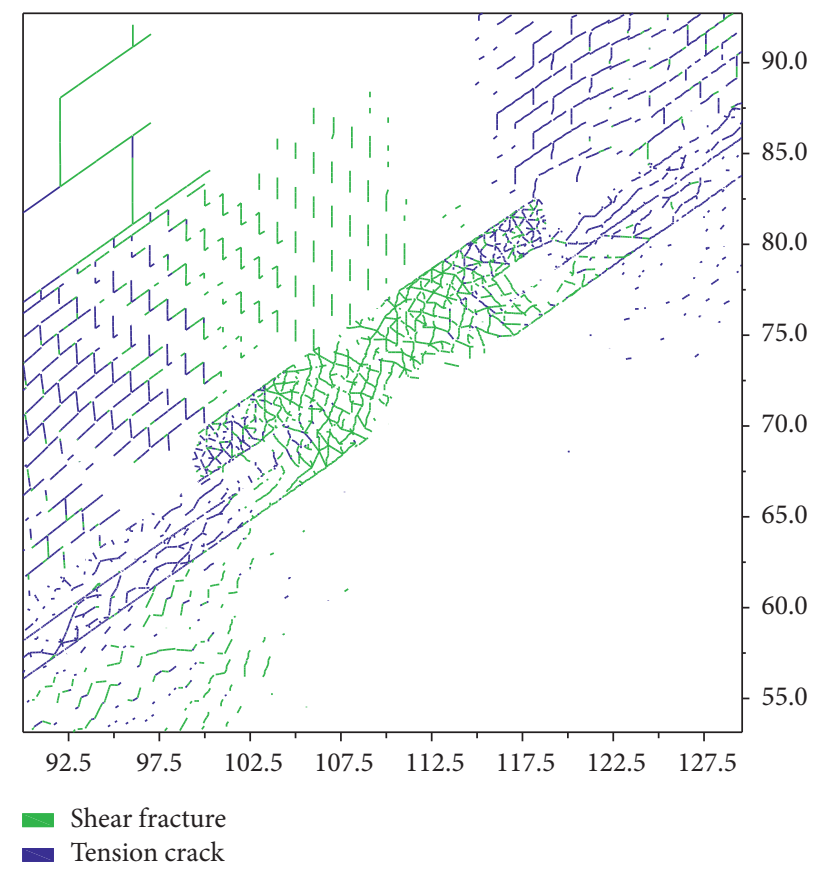

FIGURE 5: Damage characteristics of floor rock. 


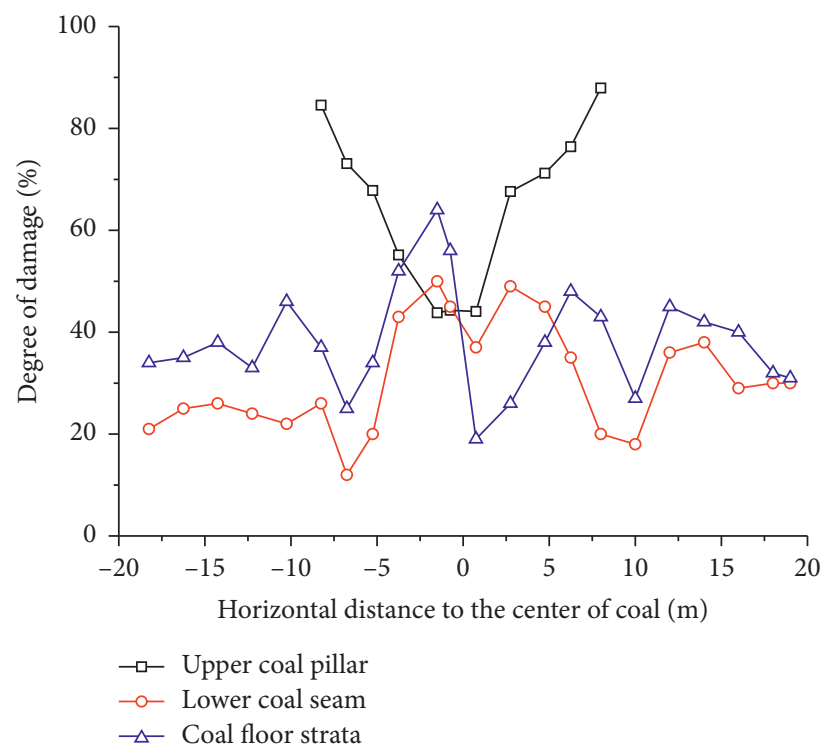

FIgURE 6: Damage distribution law of floor strata.

TABLE 2: The distance between roof and upper coal seam of 12032 haulage roadway.

\begin{tabular}{|c|c|c|c|c|c|c|c|}
\hline Distance to open-off cut $L(\mathrm{~m})$ & $0-55$ & $55-200$ & $200-235$ & $235-310$ & $310-465$ & $465-620$ & $620-710$ \\
\hline Roadway length $l(\mathrm{~m})$ & 55.0 & 145.0 & 35.0 & 75.0 & 155.0 & 55.0 & 90.0 \\
\hline Roof thickness $H(\mathrm{~m})$ & $1.50-1.75$ & $0.85-1.50$ & $1.50-2.00$ & $2.00-2.50$ & $2.50-3.00$ & $3.00-3.50$ & $3.50-3.90$ \\
\hline Roof classification type & II & I & II & II & III & III & IV \\
\hline
\end{tabular}

TABLE 3: Speculates the distance between the roof of the 12032 tailgates and the upper coal seam.

\begin{tabular}{|c|c|c|c|c|c|c|c|}
\hline Distance to open-off cut $L(\mathrm{~m})$ & $0-40$ & $40-155$ & $155-230$ & $230-325$ & $325-390$ & $390-660$ & $660-690$ \\
\hline Roadway length $l(\mathrm{~m})$ & 40.0 & 115.0 & 75.0 & 95.0 & 65.0 & 270.0 & 30.0 \\
\hline Roof thickness $H(\mathrm{~m})$ & $2.20-2.50$ & $2.50-2.80$ & $2.00-2.50$ & $2.50-3.20$ & $2.20-2.50$ & $2.50-3.50$ & $3.50-3.70$ \\
\hline Roof classification type & II & II & II & III & II & III & IV \\
\hline
\end{tabular}

TABle 4: Classification of coal roof types.

\begin{tabular}{lcc}
\hline Classification type & Characteristics of roof types & Thickness between coal seams (m) \\
\hline I & Broken loose roof & $H \leq 1.5$ \\
II & Crack through roof & $1.5<H \leq 2.5$ \\
III & Fractured roof & $2.5<H \leq 3.5$ \\
IV & Partially complete roof & $H>3.5$ \\
\hline
\end{tabular}

Type III (fissures developed roof): there are number of fissures and cracks existing in the surrounding rock which attributed to the mining activities. However, these fissures and cracks are not perforated. In this case, the interface between the coal seam and surrounding rocks is not strong enough, resulting in the reduction of the strength of the surrounding strata. If the distance between each coal seam falls into $2.5 \mathrm{~m}$ to $3.5 \mathrm{~m}$, the excavation of the lower coal seam may result in the repeated unloading and destruction of the interlayer rock mass.
Type IV (relative intact roof): if the distance between the coal seams is larger than $3.5 \mathrm{~m}$, the influence of the excavation of the lower coal seam will not significantly affect the intact of the upper coal seam. In this case, there is no dangerous for the roof controlling.

\section{Filed Study}

6.1. Asymmetric and Partition Support Technique. With the consideration of the variable thickness of overlying strata, the asymmetric and partition support technique was 
TABLE 5: The main support forms of mining roadway.

\begin{tabular}{lccc}
\hline Classification type & Characteristics of roof types & Roof support form & Support form of roadway side \\
\hline I & Broken loose roof & Hydraulic expansion bolt + shed support & Shed support + anchor cable support \\
II & Crack through roof & Short bolt + Anchor cable & Short bolt + short anchor cable \\
III & Fractured roof & Bolt + Anchor cable & Bolt + short anchor cable \\
IV & Partially complete roof & & \\
\hline
\end{tabular}

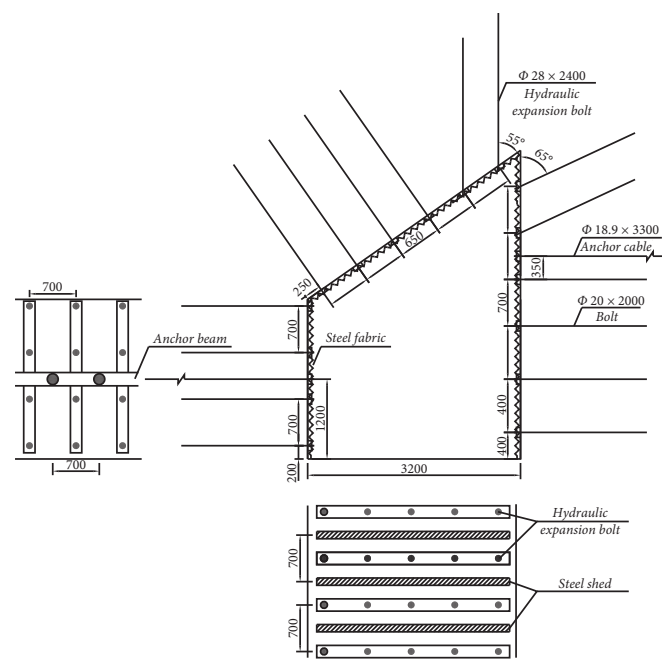

(a)
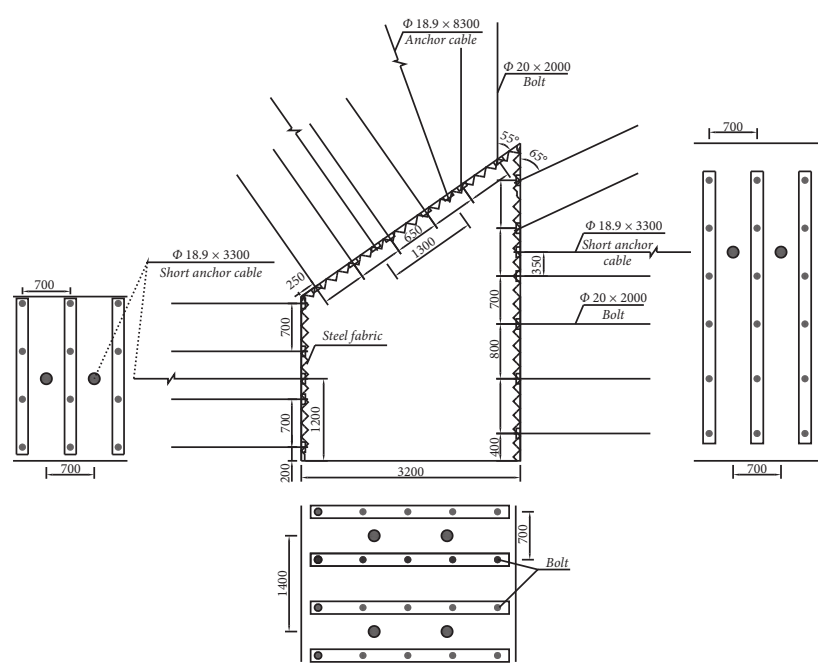

(b)

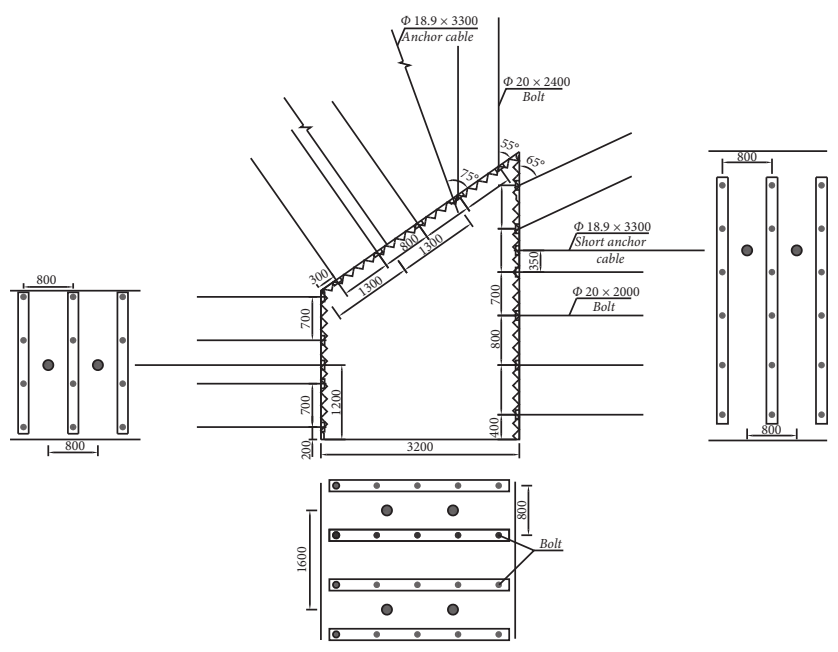

(c)

FIGURE 7: Support section of the roadway: (a) class-I roof roadway, (b) class-II roof roadway, and (c) class-III/IV roof roadway.

currently proposed based on the classification of the roof conditions and the values of the damage coefficient discussed above. The support forms and critical parameters of the 12032 Longwall mining roadway are shown in Table 5 and Figure 7, in which different support patterns are presented in detail.

6.2. Verification of the Proposed Support Technique. To verify the feasibility of proposed support technique in controlling the integrity of the roadway surrounding rock, the case study was conducted at the12032 longwall. The width and the center height of the trapezoidal roadway is $3.6 \mathrm{~m}$ and $2.8 \mathrm{~m}$, with $10.08 \mathrm{~m}^{2}$ cross-sectional area. Based on the classification of the roof conditions, the partition support technique was applied. More detailed information about the support parameters are presented below:

(1) Type-I roof condition: the hydraulic expansion bolts and I-sectional steel frame are applied. In addition, the high-strength rebar bolts together with the $\varphi 18.9 \mathrm{~mm} \times 3300 \mathrm{~mm}$ cables combined with the beam are adopted to control the deformation of the roadway ribs. The row space for bolts and steel frame 


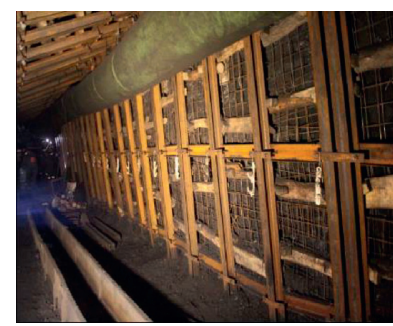

(a)

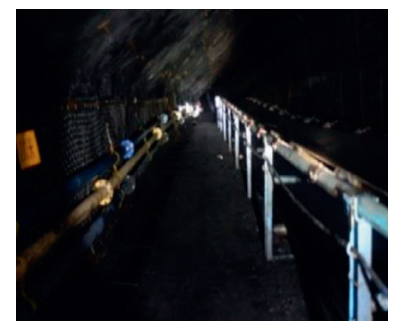

(b)

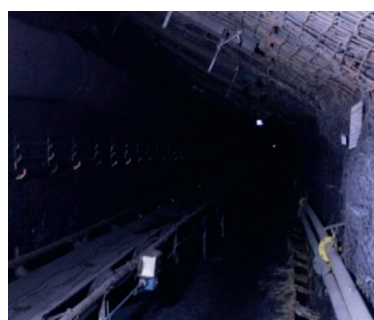

(c)

FIGURE 8: The effect of roadway support in 12032 longwall: (a) class-I roof roadway, (b) class-II roof roadway, and (c) class-III/IV roof roadway.

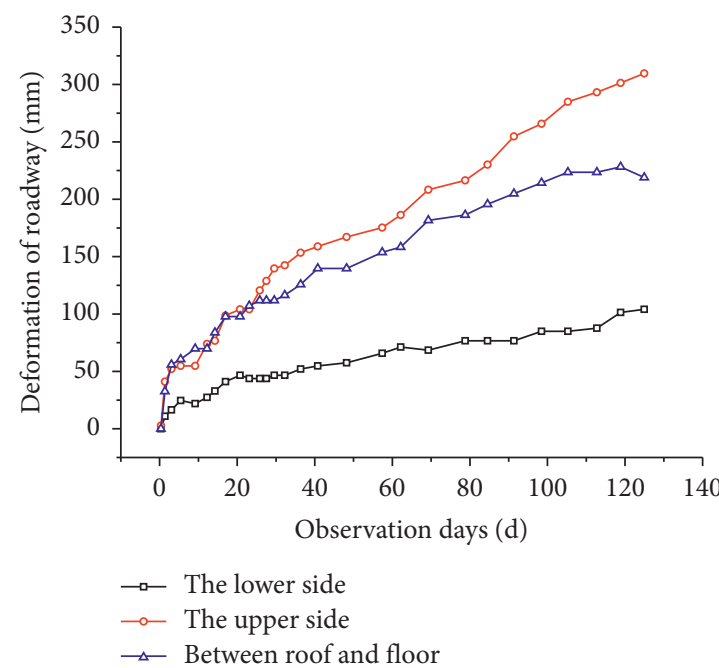

(a)

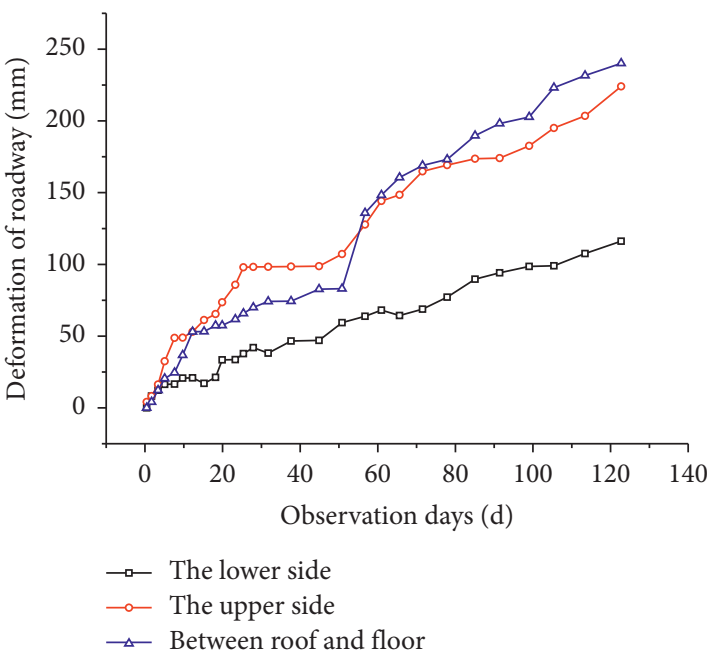

(b)

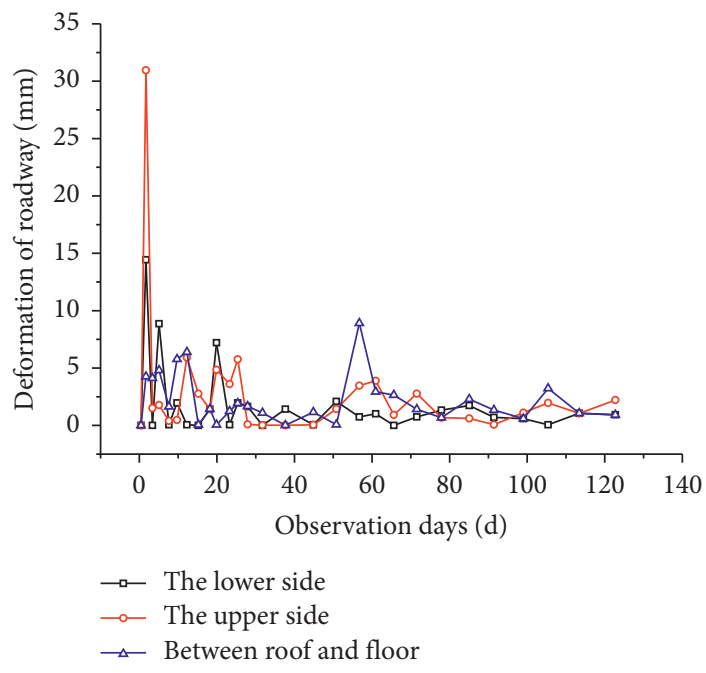

(c)

FIGURE 9: Monitoring results of roadway deformation in 12032 longwall: (a) class-I roof roadway, (b) class-II roof roadway, and (c) class-III/ IV roof roadway.

is with the constant value of $700 \mathrm{~mm}$. Note that the line space between the bolts in the roof and the ribs are $650 \mathrm{~mm}$ and $700 \mathrm{~mm}$, respectively.
(2) Type-II roof condition: the roof is supported by high-strength rebar bolts and the $\varphi 18.9 \mathrm{~mm} \times 8300 \mathrm{~mm}$ cables with the additional 
pressure release apparatus, and the row space and line space of roof support are $700 \mathrm{~mm}$ and $650 \mathrm{~mm}$, respectively. The high-strength bolts and the $\varphi 18.9 \mathrm{~mm} \times 3300 \mathrm{~mm}$ cables are also used to maintain the stability of the roadway ribs. The same value of the line space and row space (i.e., $700 \mathrm{~mm}$ ) for rib supports are adopted.

(3) Type III/IV roof conditions: the high-strength rebar bolts and cables were used as the primary support. Different from the above support design, the larger value $(800 \mathrm{~mm})$ of the row space was adopted for roof support. In addition, the value of the line space for rib support also increased to $800 \mathrm{~mm}$ and $700 \mathrm{~mm}$, respectively.

As depicted in Figures 8 and 9, the deformation of surrounding rock with type-I roof condition is $219 \mathrm{~mm}$ in axial direction and $412 \mathrm{~mm}$ along the horizontal direction, respectively. The values of this mentioned deformation are $224 \mathrm{~mm}$ and $356 \mathrm{~mm}$ for the roadway with the type-II roof. The deformation of the roof, floor, and ribs is with the smaller values when the support technique was adopted for the roadway with type-II roof condition. It indicated that the proposed partition support technique is effective and feasible in sustaining the integrity of surrounding rock.

\section{Conclusion}

This paper presents a comprehensive research on the stability controlling of the roadway driven in the steeply dipping coal seam with close distance. The detailed numerical simulation was carried out via the Universal Distinct Element Code (UDEC) based on the concise analysis of the geological and mining conditions of the research area, followed by the classification of the roof conditions with the consideration of the damage coefficient. The case study was then conducted and the feasibility of the proposed asymmetric and partition support technique was verified. The following conclusions can be obtained from this research:

(1) There is a stress concentration on the floor of the residual coal pillar. The maximum vertical stress is generally below the centerline of the coal pillar, while the maximum horizontal stress is above the centerline of the coal pillar. Moreover, the peak shear stress above the centerline of the coal pillar is generally larger than that obtained from the other side.

(2) The roadway roof are classified into four groups based on the actual exposure of the strata, which are broken and loose roof, crack-extended roof, fissures developed roof, and relative intact roof, respectively.

(3) It is feasible to use the asymmetric and partition support technique to maintain the stability of the surrounding rock, as verified by the case study conducted at the 12032 longwall.

Note that the surrounding rock of the roadway is a heterogeneous material in nature, which is not well accounted for in the present research. To obtain the in-depth understanding about the deformation characteristic of surrounding rock of steeply dipping coal seam, the further research with the consideration of initial cracks in surrounding rock should be well considered.

\section{Data Availability}

The research data used to support the findings of this study are currently under embargo while the research findings are commercialized. Requests for data, 12 months after publication of this article, will be considered by the corresponding author.

\section{Conflicts of Interest}

The authors declare that they have no conflicts of interest.

\section{Authors' Contributions}

H. L. and C. X. conceptualized the study; H. L. and H. W. carried out formal analysis; H. L. and G. L. investigated the study; H. L., C. X., and S. F. wrote and prepared the original draft; H. L. and H. W. reviewed edited the manuscript; H. L. and G. L. supervised the study.

\section{Acknowledgments}

The authors would like to thank the technical support from ZhongWei coal mine in sampling and on-site investigation. The research was financially supported by the Natural Science Foundation of Xinjiang Uyghur Autonomous Region (2019D01C023), Natural Science Foundation of China (51964043 and U1903216), and PhD Research Startup Fund of Xinjiang University (no. BS620321027).

\section{References}

[1] D. S. Zhang, H. L. Liu, G. Fan, and X. Wang, "Connotation and prospection on scientific mining of large Xinjiang coal base," Journal of Mining \& Safety Engineering, vol. 32, no. 1, pp. 1-6, 2015.

[2] J. Ning, J. Wang, T. Bu, S. Hu, and X. Liu, “An innovative support structure for gob-side entry retention in steep coal seam mining," Minerals, vol. 7, no. 5, p. 75, 2017.

[3] S. Liu, K. Yang, C. Tang, and X. Chi, "Rupture and migration law of disturbed overburden during slicing mining of steeply dipping thick coal seam," Advances in Civil Engineering, vol. 2020, Article ID 8863547, 11 pages, 2020.

[4] H. L. Liu, W. X. Cao, C. F. Shan et al., "Similar simulation experimental study on fracture charac-teristics of overburden strata under mining with large dip angle," Journal of Xinjiang University (Natural Science Edition in Chinese and English), vol. 37, no. 3, pp. 301-308, 2020.

[5] Y. P. Wu, "Study on dynamics controlling basis of system " $\mathrm{R}$ S - F"' in Steeply Dipping Seam MiningXi'an University of Science and Technology, Xi'an, China, 2003.

[6] W. Lv, Y. Wu, L. Ming, and J. Yin, "Migration law of the roof of a composited backfilling longwall face in a steeply dipping coal seam," Minerals, vol. 9, no. 3, p. 188, 2019.

[7] H. W. Wang, Research on Evolution of Stress and Structural Stability of Surrounding Rock in the Longwall Mining of Steeply Dipping Seam, Xi'an University of Science and Technology, Xi'an, China, 2014. 
[8] H. S. Tu, S. H. Tu, C. Zhang, L. Zhang, and X. G. Zhang, "Characteristics of the roof behaviors and mine pressure manifestations during the mining of steep coal seam," Archives of Mining Sciences, vol. 62, no. 4, pp. 871-891, 2017.

[9] H.-s. Tu, S.-h. Tu, D.-f. Zhu, D.-y. Hao, and K.-j. Miao, "ForceFracture characteristics of the roof above goaf in a steep coal seam: a case study of xintie coal mine," Geofluids, vol. 2019, Article ID 7639159, 11 pages, 2019.

[10] J. P. Xiao, K. Yang, S. Liu, and B. Zhou, "Study on breaking mechanism of overlying strata in deeply inclined coal seam," Journal of Safety Science and Technology, vol. 15, no. 3, pp. 75-80, 2019.

[11] X. Y. Kong, K. Yang, and W. Lu, "Floor failure mechanism and engineering application of downward mining of the large dip angle coal seam group," Chinese Journal of Underground Space and Engineering, vol. 36, no. S2, pp. 394-400, 2015.

[12] K. Yang, X. Y. Kong, W. Lu, and S. Liu, "Study of strata pressure behaviors with longwall mining in large inclination and thick coal seam under closed distance mined gob," Chinese Journal of Rock Mechanics and Engineering, vol. 9, no. S2, pp. 4278-4285, 2015.

[13] Z. Zhang, M. Deng, X. Wang, W. Yu, F. Zhang, and V. D. Dao, "Field and numerical investigations on the lower coal seam entry failure analysis under the remnant pillar," Engineering Failure Analysis, vol. 115, Article ID 104638, 2020.

[14] Z. Zhang, M. Deng, J. Bai, S. Yan, and X. Yu, "Stability control of gob-side entry retained under the gob with close distance coal seams," International Journal of Mining Science and Technology, vol. 31, no. 2, pp. 321-332, 2021.

[15] F. Q. Gao, D. Stead, and H. Kang, "Numerical simulation of squeezing failure in a coal mine roadway due to mining-induced stresses," Rock Mechanics and Rock Engineering, vol. 48, no. 4SI, pp. 1635-1645, 2015.

[16] F. Q. Gao, Simulation of Failure Mechanisms Around Underground Coal Mine Openings Using Discrete Element Modelling, Simon Fraser University, Burnaby, Canada, 2013.

[17] M. Ju, X. Li, Q. Yao, S. Liu, S. Liang, and X. Wang, "Effect of sand grain size on simulated mining-induced overburden failure in physical model tests," Engineering Geology, vol. 226, pp. 93-106, 2017.

[18] F. Q. Gao and D. Stead, "The application of a modified Voronoi logic to brittle fracture modelling at the laboratory and field scale," International Journal of Rock Mechanics and Mining Sciences, vol. 68, pp. 1-14, 2014.

[19] T. Kazerani and J. Zhao, "Micromechanical parameters in bonded particle method for modelling of brittle material failure," International Journal for Numerical and Analytical Methods in Geomechanics, vol. 34, no. 18, pp. 1877-1895, 2010.

[20] W.-d. Wu, J.-b. Bai, X.-y. Wang, S. Yan, and S.-x. Wu, "Numerical study of failure mechanisms and control techniques for a gob-side yield pillar in the s coal mine, China," Rock Mechanics and Rock Engineering, vol. 52, no. 4, pp. 1231-1245, 2019.

[21] Z. Zhang, M. Deng, J. Bai, X. Yu, Q. Wu, and L. Jiang, "Strain energy evolution and conversion under triaxial unloading confining pressure tests due to gob-side entry retained," International Journal of Rock Mechanics and Mining Sciences, vol. 126, Article ID 104184, 2020.

[22] L. Zhang and H. H. Einstein, "Using RQD to estimate the deformation modulus of rock masses," International Journal of Rock Mechanics and Mining Sciences, vol. 41, no. 2, pp. 337-341, 2004.

[23] C. Zhang, S. H. Tu, and L. Zhang, "Study of stress sensitivity of coal samples with different mining damage in overlying strata," Journal of China University of Mining \& Technology, vol. 47, no. 3, pp. 502-511, 2018.

[24] Y. J. Yang, D. C. Wang, M. F. Guo et al., "Study of rock damage characteristics based on acoustic emission tests under triaxial compression," Chinese Journal of Rock Mechanics and Engineering, vol. 33, no. 1, pp. 98-104, 2014. 